\title{
Custo da produção agrícola: uma análise do cultivo da soja em uma propriedade rural de Júlio de Castilhos/RS, safra 2016/2017
}

\author{
Pós-Graduação em andamento em Gestão Tributária - Verbo Educacional pela \\ Universidade Federal de Santa Maria - UFSM \\ Av. Roraima, 1000. Camobi. Santa Maria/RS. CEP: 97105-900 \\ E-mail: yvelisepiccinin@hotmail.com \\ Marivane Vestena Rossato \\ Doutorado em Economia Aplicada pela Universidade Federal de Viçosa - UFV \\ Professora na Universidade Federal de Santa Maria - UFSM \\ Av. Roraima, 1000. Camobi. Santa Maria/RS. CEP: 97105-900 \\ E-mail:marivavest@gmail.com
}

\section{RESUMO}

A atividade de agricultura consiste em importante fonte de renda para diversas famílias que dela se utilizam. Além disso, esta atividade apresenta diversos riscos atrelados às suas características peculiares. Desse modo, a problemática desta pesquisa consistiu na falta de dados e informações de caráter operacional que pudessem delimitar os custos atrelados à atividade do cultivo da soja, bem como a avaliação do custo médio da saca de soja produzida em uma propriedade rural do município de Júlio de Castilhos/RS. Nesse enfoque, objetivou-se responder a tal problemática mediante a caracterização do cultivo da soja e da propriedade, onde se identificaram e avaliaram os gastos associados ao cultivo e à comercialização da soja na propriedade rural para, posteriormente, se apurar o custo médio da saca de soja produzida na safra 2016/2017. Em seus aspectos metodológicos, a pesquisa se caracteriza como sendo de natureza qualitativa; para o atendimento dos seus objetivos, consiste em uma pesquisa descritiva e estudo de caso. Sob o aspecto dos procedimentos adotados, utilizaram-se pesquisas bibliográficas e documentais, observação e técnica de levantamento denominada entrevista semiestruturada. Dentre os principais resultados, destaca-se que o cultivo da soja apresentou um lucro de $R \$ 106.004,57$ e o custo médio da saca de soja produzida é de $\mathrm{R} \$ 22,62$. Por fim, o custo de produção representa aproximadamente $37,27 \%$ da receita bruta gerada.

Palavras-chave: Atividade Rural. Cultivo da Soja. Custo da Atividade.

Cost of agricultural production: an analysis of soybean cultivation in a rural property of Júlio de Castilhos/RS, harvest 2016/2017 
Custo da produção agrícola: uma análise do cultivo da soja em uma propriedade rural de Júlio de Castilhos/RS, safra 2016/2017

Yvelise Piccinin, Marivane Vestena Rossato

\section{ABSTRACT}

The agricultural activity consists of important source of income for several families, which get their livelihood from agriculture. Moreover, this activity presents various risks related to its peculiar characteristics. That way, the problem of this research consisted in the absence of operational data and information that clouded limit the costs linked to the activity of soybean cultivation, as well as the evaluation of the average cost of the soybean sack produced in a rural property in the municipality of Júlio de Castilhos/RS. The objective of this approach was to respond to this problem through the characterization of soybean cultivation and of the property, where the costs associated with the cultivation and commercialization of soybean were identified and verified in the rural property, determining if the average cost of the produced soy soybean bag in the $2016 / 2017$ harvest. In its methodological aspects, the research characterizes as a qualitative in nature; in order to meet its objectives, this is a descriptive and a case study research. In terms of the adopted procedures, this one is used of bibliographical and documentary researches; of observation; and, the survey technique called semistructured interview. Among the main results, the soybean crop showed a profit of $R \$ 106,004.57$ and the average cost of the soybean sack produced is $R \$ 22.62$. Finally, the cost of production represents approximately $37.27 \%$ of the gross revenue generated.

Keywords: Rural Activity. Soybean cultivation. Cost of the Activity.

\section{INTRODUÇÃO}

A agricultura, desde muito tempo, destaca-se como a base da cadeia econômica brasileira. Os agricultores, mediante o emprego de sua mão de obra, de recursos produtivos e tecnologias, cultivam a terra com fins de satisfazer as necessidades humanas e gerar renda para si e sua família.

Além disso, as principais contribuições dessa atividade para o país encontram-se nos aspectos de retorno financeiro por meio da exportação, geração de matérias primas para as indústrias, bem como a produção de alimentos que abasteçam o mercado nacional (Freitas, Kesseler, Piccinin, Rossato, \& Dorr, 2014). Os principais produtos cultivados e exportados pelo Brasil, de acordo com Crepaldi (2016), são: café, açúcar e a soja. No que diz respeito à cultura da soja, o Brasil, no cenário atual, apresenta-se 
Custo da produção agrícola: uma análise do cultivo da soja em uma propriedade rural de Júlio de Castilhos/RS, safra 2016/2017

Yvelise Piccinin, Marivane Vestena Rossato

como um dos líderes mundiais na produção do mesmo, juntamente com os Estados Unidos, a Argentina, a China, a Índia e o Paraguai (EMBRAPA, 2016).

Cabe destacar que os produtores rurais estão sujeitos a diversas adversidades relacionadas a: alta dependência do clima; agentes biológicos; variação da oferta e da demanda; produto com elevada perecibilidade; ciclo biológico da produção. Logo, pelos fatores evidenciados, constata-se que o risco atrelado à produção agrícola pode ser considerado elevado. Também compete mencionar que toda produção gera custos ao produtor, e estes são volumosos, devido aos diversos insumos que são demandados.

Também, de acordo com Batalha \& Queiroz (2003), a "[...] gestão das empresas rurais é, na maior parte das vezes, focalizada nas técnicas de produção e conceitos operacionais de atividades específicas desenvolvidas, em detrimento das informações financeiro/administrativas". Prontamente, justifica-se a relevância por meio dos fatores anteriores apresentados, atrelada à importância que um controle dos gastos dos insumos utilizados na produção, visto que possibilitaria ao agricultor o acesso a informações em tempo hábil para se obter a melhor alternativa em relação ao gerenciamento de seu patrimônio.

Desse modo, a problemática desta pesquisa consistiu na falta de dados e informações de caráter operacional que pudessem delimitar os custos atrelados à atividade do cultivo da soja, bem como a avaliação do custo médio da saca de soja produzida em uma propriedade rural do município de Júlio de Castilhos/RS. Nesse enfoque, o objetivo geral foi avaliar o custo total de produção e o custo médio da saca de soja produzida nessa propriedade na safra de 2016/2017.

Especificamente, o estudo atendeu os seguintes objetivos: (a) caracterizar o cultivo da soja e a propriedade; (b) identificar e apurar os gastos associados ao cultivo e comercialização da soja na propriedade rural; (c) apurar o resultado obtido com a cultura da soja na safra 2016/2017; e (d) mensurar o custo médio da saca de soja produzida e o percentual do custo em relação a receita bruta.

Este trabalho apresenta, além da introdução ora apresentada, o referencial teórico na sequência; após, os métodos e técnicas utilizados. Também discute e 
Custo da produção agrícola: uma análise do cultivo da soja em uma propriedade rural de Júlio de Castilhos/RS, safra 2016/2017

Yvelise Piccinin, Marivane Vestena Rossato

apresenta os resultados obtidos; e, por fim, apresenta a conclusão e as referências que embasaram todo o estudo.

\section{REFERENCIAL TEÓRICO}

\subsection{Contabilidade}

A contabilidade é conceituada como "[...] uma ciência social que tem por objeto o controle do patrimônio das organizações" (Marion \& Ribeiro, 2011). Neste estudo, utilizaram-se os ramos da Contabilidade de Custos e Contabilidade Rural.

\subsubsection{Contabilidade de custos}

A contabilidade de custos, conforme Leone \& Leone (2010), "[...] se destina a produzir informações para os diversos níveis gerenciais de uma entidade, como auxílio às funções de determinação de desempenho, de planejamento e controle das operações e de tomada de decisões". Este ramo possui uma metodologia conceitual própria para classificar e ordenar os diferentes itens que compõem suas avaliações e ferramentais. Dentre eles, citam-se: o gasto, o desembolso, o custo, a despesa, a perda, entre outros. Todos são conceitos fundamentais para esse ramo da contabilidade.

Incialmente, os gastos, de acordo com Ribeiro (2015), ocorrem "[...] toda vez que a empresa industrial pretende obter bens - seja para uso, troca, transformação ou consumo - ou utilizar algum tipo de serviço, ela efetua um gasto. Esses gastos, que podem ser pagos à vista ou a prazo, classificam-se em investimentos, despesas e custos". Martins (2010) classifica os gastos realizados como investimento quando este é "[...] ativado em função de sua vida útil ou de benefícios atribuíveis a futuro(s) período(s)". Ribeiro (2015) coloca que a despesa "[...] compreende os gastos decorrentes do consumo de bens e da utilização de serviços das áreas administrativa, comercial e financeira, que direta ou indiretamente visam obtenção de receitas". 
Custo da produção agrícola: uma análise do cultivo da soja em uma propriedade rural de Júlio de Castilhos/RS, safra 2016/2017

Yvelise Piccinin, Marivane Vestena Rossato

Por outro lado, Martins (2010) considera como custo o "[...] gasto relativo a bem ou serviço utilizado na produção de outros bens ou serviços". Por fim, o mesmo autor define a perda como o "[...] bem ou serviço consumido de forma anormal e involuntária [...]. São itens que vão diretamente à conta de Resultado" (Martins, 2010).

Os custos indiretos de fabricação não são alocados diretamente aos produtos, por isso precisam de algum meio para sua distribuição e incorporação. Assim, surgem diversos tipos de métodos de custeio. Dentre eles', cita-se o custeio baseado em atividades, conhecido como ABC; conforme Padoveze (2013), como um método de custeio que identifica um conjunto de custos para cada evento ou transação das atividades na organização, agindo assim como um direcionador de custos. Viceconti e Neves (2013) indicam que o pressuposto do $A B C$ é que a atribuição dos custos às atividades deverá ser feita mediante a utilização de direcionadores de recursos.

\subsubsection{Contabilidade da atividade rural}

A contabilidade rural, de acordo com Crepaldi (2016), apresenta como principais finalidades: orientar as operações agrícolas e pecuárias; mensurar o desempenho econômico-financeiro de cada atividade produtiva; apoiar a tomada de decisões no planejamento da produção, das vendas e dos investimentos; auxiliar nas projeções do fluxo de caixa e necessidade de crédito, entre outras.

\subsection{Exercício da atividade rural}

Conforme estabelecido na Lei n. 4.504/64, Art. 4.ำ inciso VI, exercício da atividade rural é "[...] o empreendimento de pessoa física ou jurídica, pública ou privada, que explore econômica e racionalmente imóvel rural, dentro de condição de rendimento econômico da região em que se situe e que explore área mínima agricultável do imóvel". 
Custo da produção agrícola: uma análise do cultivo da soja em uma propriedade rural de Júlio de Castilhos/RS, safra 2016/2017

Yvelise Piccinin, Marivane Vestena Rossato

\subsubsection{Depreciação, amortização e exaustão}

A depreciação, conforme Marion (2014), é aplicada somente aos bens tangíveis, como máquinas, equipamentos, móveis, utensílios, edifícios etc., e incide sobre as culturas permanentes que não são ceifadas (cana-de-açúcar); apenas tem seus frutos colhidos (laranjeiras, macieiras, parreiras, etc.), pois, no outro caso, estas sofrerão exaustão. A amortização ocorre "[...] nos direitos de extração de madeira de terceiros ou de exploração de pomar alheio, por prazo determinado, a preço prefixado" (Marion, 2014).

\subsection{Cultivo da soja}

O sistema de cultivo da soja, segundo Hirakuri, Debiasi, Procópio, Franchini, \& Castro (2012), refere-se às práticas comuns de manejo associadas a essa espécie vegetal, visando sua produção a partir da combinação lógica e ordenada de um conjunto de atividades e operações (Figura 1).

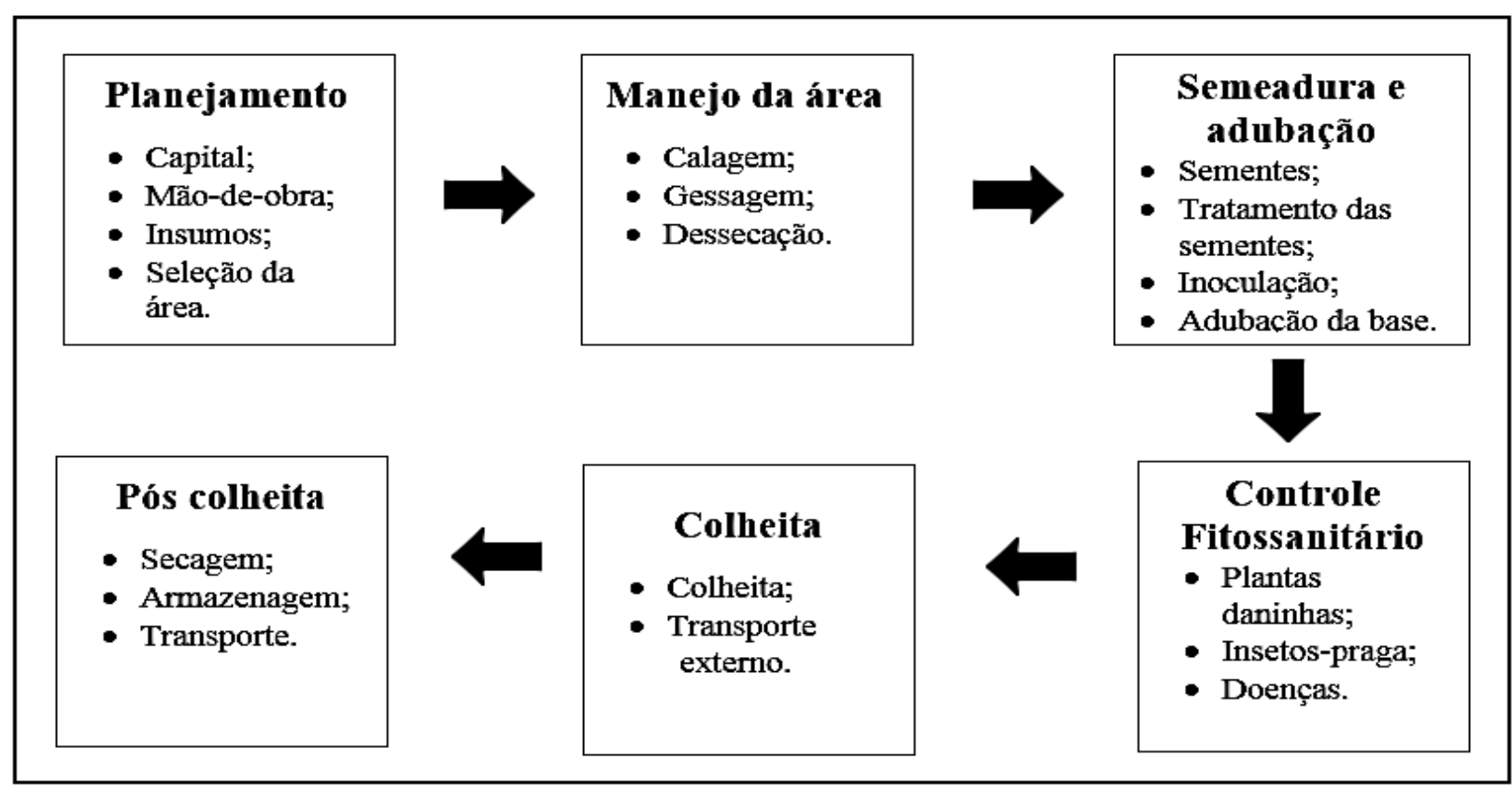

Figura 1. Sistema de cultivo da soja

Fonte: HIRAKURI et al., 2012. 
Custo da produção agrícola: uma análise do cultivo da soja em uma propriedade rural de Júlio de Castilhos/RS, safra 2016/2017

Yvelise Piccinin, Marivane Vestena Rossato

Como em qualquer atividade, o planejamento é uma das atividades mais importantes para a redução de erros/riscos e que, consequentemente, aumenta as chances de sucesso. Posteriormente, no manejo da área, incluem-se as etapas de calagem, gessagem e dessecação. Logo, o produtor, por meio da análise do solo, verifica as características da terra, determinando a necessidade do uso da calagem ou gessagem.

Outra característica peculiar referente ao plantio da soja consiste no fato de este ser realizado quase que totalmente pela técnica de plantio direto. A técnica de plantio direto exige que o solo sempre esteja coberto por plantas em desenvolvimento e por resíduos vegetais. Tal fato deve-se à finalidade de proteger o solo do impacto direto das gotas de chuva, do escorrimento superficial e das erosões hídrica e eólica (Agência Embrapa de Informação Tecnológica, 2014). Portanto, antes do plantio, deve-se aplicar herbicida com fins de dessecar as plantas ali existentes, restando a palha dessas plantas.

A terceira etapa consiste na semeadura e adubação. Na compra de sementes, é indicado que o agricultor saiba a qualidade do produto que está adquirindo. Para isso, existem laboratórios oficiais e particulares de análise de sementes que podem prestar esse tipo de serviço, informando a germinação e a qualidade sanitária da semente. A quarta etapa consiste no controle fitossanitário de insetos e pragas, plantas daninhas e demais doenças que podem comprometer a cultura da soja.

A quinta etapa consiste na realização da colheita e no transporte da lavoura até um depósito de produto. A última etapa consiste no pós-colheita, quando ocorre o armazenamento dos grãos, a secagem e, posteriormente, o transporte das sacas vendidas. $\mathrm{O}$ armazenamento e a secagem podem ocorrer em silos próprios ou podem ser terceirizados. Após a venda, a produção é despachada, geralmente aos portos, quando é exportada por via férrea ou rodoviária. 
Custo da produção agrícola: uma análise do cultivo da soja em uma propriedade rural de Júlio de Castilhos/RS, safra 2016/2017

Yvelise Piccinin, Marivane Vestena Rossato

\subsection{Estudos anteriores}

Diversos estudos demonstram a importância da avaliação dos gastos associados à produção para o gerenciamento do negócio e para a tomada de decisão do produtor rural. Schwert e Cruz (2013) realizaram um estudo que buscou valorar os produtos de uma propriedade rural do município de Dilermando de Aguiar - RS. Dentre os resultados, foi possível identificar que a comercialização de vinho, suco de uva e a prestação de serviços são as atividades que geraram uma maior Margem de Contribuição Total para a absorção dos custos fixos atrelados à estrutura atual da propriedade.

Seramim e Rojo (2016) buscaram identificar os custos de produção em duas pequenas propriedades rurais, por meio da aplicação de planilha eletrônica de controle da atividade leiteira, para oportunizar melhorias no processo de gestão financeira. Os resultados indicam a possibilidade para os pequenos produtores rurais analisados que, por meio destes controles, passem a apurar o custo real da atividade, para gerir adequadamente as despesas e executar um melhor planejamento financeiro.

Por fim, Venturini (2015) analisou a viabilidade econômica de uma lavoura de soja, cuja área plantada era de 49,31 hectares no município de Restinga Seca. Segundo o estudo, mesmo com os preços atuais expressivos, a análise foi efetuada considerando os riscos no volume colhido e os preços de comercialização com base em retrospectivas passadas dessas variáveis. Como principais resultados obtidos, constatou-se que a atividade gera valor para o agricultor desde que o preço da saca de soja seja mantido em pelo menos $\mathrm{R} \$ 70,00$.

\section{MÉTODOS E TÉCNICAS}

A pesquisa pode ser classificada por vários critérios. Quanto à abordagem do problema, esta pesquisa caracteriza-se como de natureza qualitativa. De acordo com Rodrigues (2010), a pesquisa qualitativa "[...] não emprega procedimentos estatísticos na abordagem da pesquisa. É utilizada para investigar um determinado problema de 
Custo da produção agrícola: uma análise do cultivo da soja em uma propriedade rural de Júlio de Castilhos/RS, safra 2016/2017

Yvelise Piccinin, Marivane Vestena Rossato

pesquisa, cujos procedimentos estatísticos não podem alcançar, devido à complexidade do problema".

Com fins de atender aos objetivos, a pesquisa se define como de natureza descritiva. Gil (2012) comenta que a pesquisa descritiva busca descrever as características de determinadas populações ou fenômenos ou o estabelecimento de relações entre variáveis.

Quanto aos procedimentos técnicos, a pesquisa se classifica como: bibliográfica, documental, de levantamento, observação e estudo de caso. A pesquisa bibliográfica, segundo Rodrigues (2010), é aquela "[...] desenvolvida a partir de material já publicado, constituído principalmente de livros, artigos de periódicos e, atualmente, de material disponibilizado na Internet". A natureza bibliográfica deve-se ao fato de se analisar material já publicado, dando suporte necessário às especificidades relativas à pesquisa. Desse modo, a partir da metodologia que especifica o sistema de cultivo da soja, criada por Hirakuri et al. (2012), caracteriza-se o cultivo da soja na propriedade mediante pesquisa bibliográfica.

A técnica de análise documental, conforme Michel (2015), consiste na consulta a documentos, registros pertencentes ou não ao objeto de pesquisa estudado, ao qual se recorre para buscar informações úteis para entender e analisar o problema. O uso da técnica documental justifica-se pela necessidade de se conhecer, por meio de recibos, notas fiscais e demais dados, os gastos relativos ao preparo da terra, plantio da cultura, colheita e o pós-colheita.

O uso da técnica de levantamento caracteriza-se como um meio de conseguir informações do grupo investigado a respeito do problema. Realiza-se a solicitação de informações e, posteriormente, por meio de uma análise, obtêm-se os resultados acerca dos dados coletados (Gil, 2012). A técnica de levantamento recebe contribuições de diversas ferramentas, como a entrevista (estruturada e semiestruturada) e o formulário.

O levantamento foi realizado por meio de uma entrevista semiestruturada contendo uma relação fixa de perguntas, abertas e fechadas. Quanto ao modelo de 
Custo da produção agrícola: uma análise do cultivo da soja em uma propriedade rural de Júlio de Castilhos/RS, safra 2016/2017

Yvelise Piccinin, Marivane Vestena Rossato

entrevista semiestruturada, este foi adotado tendo em vista que o roteiro de questões permite uma organização flexível e a ampliação dos questionamentos à medida que as informações vão sendo fornecidas pelo entrevistado (Belei et al., 2008). Na solicitação direta ao produtor, obtiveram-se informações acerca da propriedade investigada, relativas ao sistema produtivo, custos e despesas do cultivo e da colheita.

Como complemento, a técnica de observação fez-se necessária. Gil (2012) define a observação como uma técnica que usa os sentidos para obter aspectos da realidade, consistindo em ver, ouvir e examinar fatos ou fenômenos que se pretende investigar. A utilização desse método justifica-se pelo fato de que pôde-se constatar determinados aspectos da realidade relativos a como ocorre o preparo, plantio, tratamento, colheita e pós-colheita da cultura da soja.

Por fim, delimita-se como estudo de caso. Este consiste em "[...] uma investigação empírica de um fenômeno contemporâneo dentro de seu contexto da vida real, especialmente quando os limites entre o fenômeno e o contexto não estão claramente definidos" (Yin, 2010). Tal estudo fez-se necessário para a apuração do resultado obtido com a cultura da soja e o custo médio da saca de soja produzida. Destaca-se que o emprego desta técnica impossibilita generalizações, enquadrando-se apenas às especificidades desta propriedade.

Com a posse do levantamento de dados, o tratamento desses ocorreu pela organização e tabulação no software Microsoft Excel®. Esses quadros foram organizados, no caso do cultivo da soja, de acordo com o sistema proposto por Hirakuri et al. (2012) que seguiu de direcionador na alocação dos custos de produção. Cabe destacar que, devido ao fato de a propriedade ter sua área total subdivida em áreas menores, a análise e tabulação foi feita de maneira individualizada, permitindo avaliar os custos de cada área plantada. Posteriormente, tais dados serviram de base para a avaliação do custo médio da saca de soja produzida. 
Custo da produção agrícola: uma análise do cultivo da soja em uma propriedade rural de Júlio de Castilhos/RS, safra 2016/2017

Yvelise Piccinin, Marivane Vestena Rossato

\section{RESULTADOS}

\subsection{Caracterização do cultivo da soja e da propriedade}

$\mathrm{Na}$ etapa do planejamento, o produtor avalia as necessidades de máquinas e equipamentos, infraestrutura, mão de obra necessária, a seleção das áreas do cultivo, insumos e demais itens relevantes ao cultivo da soja. Inicialmente, caracteriza-se a propriedade no que diz respeito à área cultivada e aos maquinários e equipamentos utilizados (Quadro 1).

\begin{tabular}{|l|c|c|c|}
\hline \multicolumn{1}{|c|}{ Maquinário/ Equipamento } & Marca & Modelo & Ano \\
\hline Trator 1 & Massey Ferguson® & 290 & 2002 \\
\hline Trator 2 & New Holland® & TL 75 & 2010 \\
\hline Colheitadeira & Massey Ferguson $\AA$ & 5650 Advanced & 2004 \\
\hline Plantadeira & Semeato $\AA$ & SHM & 2001 \\
\hline Pulverizador & Jacto $\AA$ & AM 14 & 2010 \\
\hline Caminhão & Mercedes Bens $\AA$ & 1113 & 1979 \\
\hline Semeadeira & Stara & Still & 2005 \\
\hline
\end{tabular}

Quadro 1. Máquinas e equipamentos do produtor rural utilizados no cultivo da soja Fonte: Dados da pesquisa.

O trator 1 , juntamente com a plantadeira, é empregado para a realização do plantio das lavouras. Tal fato se deve à necessidade de um trator de maior potência. $\mathrm{O}$ trator 2, em conjunto com o pulverizador ou a semeadeira, é utilizado para a dessecação, tratamentos com defensivos e a semeadura do cloreto. Esse é utilizado por ter menor potência e pelo fato de ter cabine, o que reduz o contato do produtor com os defensivos utilizados. Por fim, a colheitadeira realiza a colheita da soja e o caminhão, o transporte do produto até os depósitos da cooperativa.

$\mathrm{Na}$ sequência, se estabelecem as etapas necessárias para o cultivo da soja, de acordo com a metodologia de Hirakuri et al. (2012), atrelada a dados obtidos pela técnica de levantamento, análise documental e da observação do processo produtivo, bem como à sistemática de custeio $A B C$. 
Custo da produção agrícola: uma análise do cultivo da soja em uma propriedade rural de Júlio de Castilhos/RS, safra 2016/2017

Yvelise Piccinin, Marivane Vestena Rossato

Antes do cultivo, o produtor realiza revisões nos equipamentos, efetuando reparos e manutenções, como trocas de peças, troca de óleo e lubrificação. Outro aspecto se refere à mão de obra. Esta corresponde à do produtor e, quando necessário, contrata-se um ajudante diarista para os momentos em que ele, sozinho, não consiga realizar as etapas. A área utilizada para cultivar soja equivale a 65,5 ha. $\mathrm{A}$ mesma se subdivide em 4 áreas menores, localizadas em diferentes pontos do município de Júlio de Castilhos/RS. A divisão das lavouras encontra-se demonstrada no Quadro 2. Ressalta-se que as áreas foram utilizadas para o rateio dos custos de todas as etapas do cultivo, visto que os mesmos foram individualizados por lavoura.

\begin{tabular}{|l|c|c|c|c|c|}
\hline Lavoura & Lavoura 1 & Lavoura 2 & Lavoura 3 & Lavoura 4 & Área total \\
\hline Área cultivada (em ha.) & 17,5 & 21 & 8 & 19 & 65,5 \\
\hline
\end{tabular}

Quadro 2. Descrição da área cultivada

Fonte: Dados da pesquisa.

Dentro do manejo da área, encontram-se algumas etapas. De acordo com Hirakuri et al. (2012), as etapas correspondem à: calagem, gessagem e dessecação. Ao questionar o produtor sobre esta etapa, este afirmou que a calagem foi realizada há 1 ano e que ele a realiza com a periodicidade de 2 anos. Quanto à gessagem, a resposta foi que não a realiza.

Por ser uma cultura temporária, seu cultivo na região, geralmente, ocorre nos meses de outubro a dezembro e perdura até a colheita entre os meses de março a maio do ano seguinte. Devido à existência de outra cultura na terra, como azevém e aveia e, pelo fato de o plantio da soja ser realizado na modalidade de "plantio direto", existe a necessidade de se dessecar a lavoura, visto que a palha seca da cultura anterior deve ficar na terra para o plantio da soja. A dessecagem consiste na aplicação de defensivo agrícola. O processo faz com que as plantas que estão ali sequem, restando sua palha, que serve de proteção para o solo e adubo orgânico para a cultura da soja. O tempo médio para realizar a dessecação é de $20 \mathrm{~min}$./ha. 
Custo da produção agrícola: uma análise do cultivo da soja em uma propriedade rural de Júlio de Castilhos/RS, safra 2016/2017

Yvelise Piccinin, Marivane Vestena Rossato

O primeiro passo, antes de se plantar, consiste no tratamento das sementes, sendo realizado com produtos como fungicidas, inseticidas, micronutrientes e inoculantes, pelo uso de máquinas específicas para tratá-las. O produtor em estudo não possui a máquina. Porém, por ser associado a uma cooperativa, a mesma disponibiliza aos associados a máquina para realizar o tratamento, de forma gratuita. Após este procedimento, ocorre o plantio da soja. O cultivo se realiza mecanicamente, com o uso de uma plantadeira apropriada para essa modalidade. A semente e o adubo são dispostos diretamente no solo, sem nenhum processo anterior de preparação da terra, após realizada a dessecação.

A plantadeira possui dois compartimentos: um para o adubo e outro para a semente, sendo os mesmos dispostos no solo ao mesmo tempo. Ao se questionar sobre o tempo que esta etapa demanda, o agricultor afirmou que são necessários, aproximadamente, $50 \mathrm{~min}$./ha. Aproximadamente 30 dias após o cultivo, ocorre a semeadura de cloreto de potássio. A atividade é necessária para que as plantas cresçam com maior vitalidade. O tempo médio para semear o cloreto de potássio, de acordo com o produtor, é de $10 \mathrm{~min} . / \mathrm{ha}$.

Conforme orientações do engenheiro agrônomo e experiência do produtor, além das necessidades específicas da lavoura, deve-se proceder à aplicação de defensivos agrícolas, sendo os mesmos nas modalidades de: herbicida, fungicida e inseticida. $O$ produtor especificou que as aplicações ocorrem, em média, a cada 18 dias. Para todo o cultivo, até sua maturação, são necessários de 4 a 5 tratamentos.

Com a maturação da cultura, esta chega na época da colheita realizada mecanicamente pela colheitadeira após 5 a 6 meses do plantio. A produção é disposta no caminhão, sendo levada ao depósito de uma cooperativa. Ao chegar no depósito, o veículo é pesado para evidenciar o total de produto a ser depositado. No que tange à armazenagem e secagem, o valor cobrado corresponde a $3 \%$ do volume total de produto depositado. No entanto, o produtor, por ser associado da cooperativa, fica isento desse valor, dado que a cooperativa não realiza a cobrança do serviço aos seus 
Custo da produção agrícola: uma análise do cultivo da soja em uma propriedade rural de Júlio de Castilhos/RS, safra 2016/2017

Yvelise Piccinin, Marivane Vestena Rossato

associados. Após a venda, a cooperativa se responsabiliza por todos os gastos associados ao transporte do produto vendido.

\subsection{Identificação e apuração dos custos do cultivo da soja na propriedade rural}

Neste tópico, se realiza a apuração dos custos relativos ao cultivo da soja, considerando cada uma de suas etapas, características de cada área cultivada e procedimentos realizados.

\subsubsection{Calagem e dessecação da lavoura}

O produtor realiza o processo de calagem a cada duas safras. O mesmo aplica duas toneladas $(\mathrm{t})$ de calcário por hectare cultivado. Cada tonelada de calcário custa $\mathrm{R} \$ 85,00$. A aplicação é terceirizada e custa ao produtor $\mathrm{R} \$ 20,00$ a tonelada de calcário aplicada. O custo da aplicação do calcário nas lavouras está delimitado no Quadro 3.

\begin{tabular}{|c|c|c|c|c|c|c|c|}
\hline \multirow{2}{*}{$\begin{array}{c}\text { Preço/t } \\
\text { (R\$) }\end{array}$} & \multirow{2}{*}{$\begin{array}{c}\text { Qtde/ha } \\
\text { (toneladas) }\end{array}$} & \multirow{2}{*}{$\begin{array}{c}\text { Custo/ha } \\
\text { (R\$) }\end{array}$} & \multicolumn{4}{|c|}{ Custo total (R\$) } & \multirow{2}{*}{$\begin{array}{l}\text { Custo - } \\
\text { área total } \\
\text { (R\$) }\end{array}$} \\
\hline & & & Lavoura 1 & Lavoura 2 & Lavoura 3 & Lavoura 4 & \\
\hline 105,00 & 2 & 210,00 & $3.675,00$ & $4.410,00$ & $1.680,00$ & $3.990,00$ & $13.755,00$ \\
\hline \multicolumn{3}{|c|}{ Custo por safra (R\$) } & $1.837,50$ & $2.205,00$ & 840,00 & $1.995,00$ & $6.877,50$ \\
\hline
\end{tabular}

Quadro 3. Custo do calcário em cada lavoura

Fonte: Dados da pesquisa.

Constata-se que o custo anual do calcário aplicado, nas lavouras 1, 2, 3 e 4, corresponde, respectivamente, a: $R \$ 1.837,50 ; R \$ 2.205,00 ; R \$ 840,00$ e $R \$ 1.995,00$. Ao todo, o custo com a aplicação do calcário, referente apenas a esta safra, é de $\mathrm{R} \$ 6.877,50$.

Complementarmente, para o cultivo da soja, faz-se necessária a aplicação de defensivos agrícolas, com o objetivo de dessecar as plantas que ali existem e cultivar a lavoura de soja. Assim, dependendo da cultura da planta ali existente, bem como da sua densidade e volume, faz-se necessário, em algumas lavouras, mais de uma aplicação ou diferentes agrotóxicos. No que diz respeito aos custos referentes aos 
Custo da produção agrícola: uma análise do cultivo da soja em uma propriedade rural de Júlio de Castilhos/RS, safra 2016/2017

Yvelise Piccinin, Marivane Vestena Rossato

defensivos utilizados, bem como ao combustível na etapa da dessecação, estes encontram-se expostos no Quadro 4.

\begin{tabular}{|l|c|c|c|c|c|}
\hline Etapa & $\begin{array}{c}\text { Lavoura 1 } \\
\text { (R\$) }\end{array}$ & $\begin{array}{c}\text { Lavoura 2 } \\
\text { (R\$) }\end{array}$ & $\begin{array}{c}\text { Lavoura 3 } \\
\text { (R\$) }\end{array}$ & $\begin{array}{c}\text { Lavoura 4 } \\
\text { (R\$) }\end{array}$ & $\begin{array}{c}\text { Custo total } \\
\text { (R\$) }\end{array}$ \\
\hline Defensivos & $2.177,00$ & $2.045,40$ & 444,80 & 777,10 & $5.444,30$ \\
\hline Combustível & 105,70 & 63,42 & 24,16 & 57,38 & 250,66 \\
\hline Custo total (R\$) & $\mathbf{2 . 2 8 2 , 7 0}$ & $\mathbf{2 . 1 0 8 , 8 2}$ & $\mathbf{4 6 8 , 9 6}$ & $\mathbf{8 3 4 , 4 8}$ & $\mathbf{5 . 6 9 4 , 9 6}$ \\
\hline
\end{tabular}

Quadro 4. Custo da etapa da dessecação

Fonte: Dados da pesquisa.

Percebe-se que os custos totais da etapa da dessecação totalizaram $\mathrm{R} \$ 5.694,96$, sendo também especificados por cada lavoura, ainda as lavouras 1 e 2 sofreram duas dessecações. Ressalta-se que o consumo de combustível é de $1 \mathrm{~L} / \mathrm{ha}$ e que o custo do litro é de $R \$ 3,02$.

\subsubsection{Preparo das sementes, plantio e semeadura de cloreto}

O produtor especificou que, para o cultivo das lavouras, utilizou semente própria nas lavouras 1, 2 e 3. Na lavoura 4, o mesmo realizou a compra da semente para o cultivo. Conforme o produtor, a saca com $40 \mathrm{Kg}$ foi comprada ao valor de $\mathrm{R} \$ 149,50$. Ressalta-se que, por ter sido adquirida, a mesma não necessita de tratamento com produtos como: fungicidas, inseticidas, micronutrientes e inoculantes. As sementes utilizadas, advindas da própria propriedade, necessitam deste tratamento. Neste caso, o produtor se torna responsável por realizá-lo, com o uso de máquina específica. $O$ produtor não possui a máquina e, deste modo, faz uso da cedida pela cooperativa da qual o produtor faz parte, sem custo ao associado.

No Quadro 5, delimita-se o custo da semente utilizada no cultivo da lavoura 4.

\begin{tabular}{|c|c|c|c|c|}
\hline $\begin{array}{c}\text { Peso da saca } \\
(\mathbf{K g})\end{array}$ & Custo/saca (R\$) & $\begin{array}{c}\text { Qtde./ha } \\
(\mathbf{K g})\end{array}$ & $\begin{array}{c}\text { Custo da semente/ha } \\
(\mathbf{R} \mathbf{\$})\end{array}$ & Custo total (R\$) \\
\hline 40 & 149,50 & 70 & 261,63 & $4.970,88$ \\
\hline
\end{tabular}

Quadro 5. Custo da semente - Lavoura 4

Fonte: Dados da pesquisa. 
Custo da produção agrícola: uma análise do cultivo da soja em uma propriedade rural de Júlio de Castilhos/RS, safra 2016/2017

Yvelise Piccinin, Marivane Vestena Rossato

Observa-se que o custo relativo à semente utilizada na lavoura 4 corresponde a $\mathrm{R} \$ 261,63$ por hectare e $\mathrm{R} \$ 4.970,88$ no total (19 hectares). Como não existe a informação do custo da semente própria utilizada, visto que o produtor não tem por hábito apurar o custo de produção da soja, optou-se, para estabelecer e buscar uma maior precisão, pela adoção, nessa safra, do custo da semente produzida na lavoura 4.

Salienta-se que, mesmo este não sendo o valor correspondente ao custo da semente de soja do ano anterior, entende-se ser o custo da semente própria utilizada mais próximo do custo da produção da lavoura 4 do que do custo da semente obtida no mercado, visto que o valor da saca comprada se apresentava bastante elevado, sendo fator crucial para a opção do produtor pelo uso da semente própria.

Com base nos dados do Quadro 19, verifica-se que o custo de produção na lavoura 4 corresponde a $R \$ 32.731,49$. Ainda, a produção nesta área foi de 1.235 sacas de soja de $60 \mathrm{Kg}$ (74.100 Kg de soja, em 19 hectares). O custo da saca de soja (60Kg) produzida na lavoura 4 expressa-se no Quadro 6.

\begin{tabular}{|c|c|c|}
\hline Custo de produção da soja (R\$) & Produção (sacas de 60 Kg) & Custo/saca(R\$) \\
\hline $32.731,49$ & 1235 & 26,50 \\
\hline
\end{tabular}

Quadro 6. Custo da saca de soja - Lavoura 4 Fonte: Dados da pesquisa.

O custo da saca de 60 quilos produzida na lavoura 4 corresponde a $R \$ 26,50$. No Quadro 7, apresenta-se o gasto com semente utilizada no plantio destas áreas.

\begin{tabular}{|c|c|c|c|c|c|}
\hline Lavoura & $\begin{array}{c}\text { Custo semente - } \\
\text { Lavoura 4 (saca 60 Kg) }\end{array}$ & $\begin{array}{c}\text { Qtde/ha } \\
\text { (Kg) }\end{array}$ & $\begin{array}{c}\text { Qtde/ha } \\
\text { (saca 60Kg) }\end{array}$ & $\begin{array}{c}\text { Custo } \\
\text { semente/ha }\end{array}$ & $\begin{array}{c}\text { Custo total } \\
\text { sementes (R\$) }\end{array}$ \\
\hline Lavoura 1 & 26,50 & 72 & 1,20 & 31,80 & 556,50 \\
\hline Lavoura 2 & 26,50 & 70 & 1,17 & 30,92 & 649,25 \\
\hline Lavoura 3 & 26,50 & 60 & 1 & 26,50 & 212,00 \\
\hline
\end{tabular}

Quadro 7. Custo da semente utilizada no plantio - Lavouras 1, 2 e 3

Fonte: Dados da pesquisa. 
Custo da produção agrícola: uma análise do cultivo da soja em uma propriedade rural de Júlio de Castilhos/RS, safra 2016/2017

Yvelise Piccinin, Marivane Vestena Rossato

De acordo com o produtor, utilizaram-se quantidades de soja diferentes para cada lavoura, devido às condições do solo, que podem prejudicar o desenvolvimento de algumas sementes, o que justifica o uso de quantidades maiores. Observa-se que o custo com a semente da soja utilizada na lavoura 1 corresponde a $R \$ 556,50$; na dois, $R \$ 649,25$; e, na lavoura 3, $R \$ 212,00$.

Por fazer uso de semente própria, o produtor necessita fazer o tratamento dela. A máquina é cedida gratuitamente pela cooperativa e funciona manualmente. No Quadro 8, apresenta-se o custo do tratamento das sementes de soja, feito pelo produtor.

\begin{tabular}{|c|c|c|c|c|c|c|c|c|}
\hline \multirow[b]{2}{*}{ Produto } & \multirow{2}{*}{$\begin{array}{l}\text { Qtde. } \\
\text { produto/ } \\
\text { saca (I) }\end{array}$} & \multirow[b]{2}{*}{$\begin{array}{c}\text { Preço/I } \\
\text { (R\$) }\end{array}$} & \multirow{2}{*}{$\begin{array}{l}\text { Qtde. } \\
\text { tratada } \\
\text { (sacas) }\end{array}$} & \multirow{2}{*}{$\begin{array}{c}\text { Custo } \\
\text { total } \\
(R \$)\end{array}$} & \multirow{2}{*}{$\begin{array}{l}\text { Custo do } \\
\text { tratamento/ } \\
\text { saca(R\$) }\end{array}$} & \multicolumn{3}{|c|}{ Custo tratamento da semente (R\$) } \\
\hline & & & & & & $\begin{array}{l}\text { Lavoura } 1 \\
\text { (21 sacas) }\end{array}$ & $\begin{array}{c}\text { Lavoura } 2 \\
\text { ( } 24,5 \text { sacas) }\end{array}$ & $\begin{array}{c}\text { Lavoura } 3 \\
\text { (8 sacas) }\end{array}$ \\
\hline$\underset{\AA}{\text { Standak }}$ & 0,1 & 1 & 53,5 & 773,08 & 12 & 303,45 & 354,03 & 115,60 \\
\hline
\end{tabular}

Quadro 8. Custo do tratamento da semente de soja própria Fonte: Dados da pesquisa.

O tratamento da semente de soja própria resultou em um custo total de $R \$ 773,08$. Em cada lavoura (1, 2 e 3), este foi de $R \$ 303,45$, $R \$ 354,03$ e $R \$ 115,60$, respectivamente.

Para a realização do plantio, foram utilizadas diferentes quantidades de adubo para cultivar cada hectare. O produtor justifica pelas características do solo. O custo da saca de $60 \mathrm{Kg}$ de adubo utilizado custa $R \$ 85,00$. O gasto relativo ao combustível utilizado na etapa de plantio da soja foi obtido com base no preço do combustível $(R \$ 3,02)$, da quantidade utilizada por hectare $(7 \mathrm{~L} / \mathrm{ha}$.) e do total da área cultivada. Essa etapa do processo (plantio) requer a utilização de 2 operadores, um para conduzir o trator (produtor rural) e outro para monitorar o funcionamento da plantadeira, sendo esta atividade realizada por auxiliar diarista contratado. Este auxiliar cobrou o valor de $\mathrm{R} \$ 100,00$ por dia. No Quadro 9, apresentam-se os custos com semente, tratamento, mão de obra, combustível e adubo para a etapa do plantio. 
Custo da produção agrícola: uma análise do cultivo da soja em uma propriedade rural de Júlio de Castilhos/RS, safra 2016/2017

Yvelise Piccinin, Marivane Vestena Rossato

\begin{tabular}{|c|c|c|c|c|c|}
\hline Produto & $\begin{array}{c}\text { Lavoura } \\
\mathbf{1 ( R \$ )}\end{array}$ & $\begin{array}{c}\text { Lavoura } \\
\mathbf{2 ( R \mathbf { R }}\end{array}$ & $\begin{array}{c}\text { Lavoura } \\
\mathbf{3 ( R \boldsymbol { } )}\end{array}$ & Lavoura 4(R\$) & $\begin{array}{c}\text { Custo } \\
\text { total(R\$) }\end{array}$ \\
\hline Sementes & 556,50 & 649,25 & 212,00 & $4.970,88$ & $6.388,63$ \\
\hline Adubo & $8.925,00$ & $10.710,00$ & $4.250,00$ & $8.075,00$ & $31.960,00$ \\
\hline Combustível & 369,95 & 443,94 & 169,12 & 401,66 & $1.384,67$ \\
\hline Mão-de-obra & 200,00 & 200,00 & 100,00 & 200,00 & 700,00 \\
\hline Custo total (R\$) & $\mathbf{1 0 . 0 5 1 , 4 5}$ & $\mathbf{1 2 . 0 0 3 , 1 9}$ & $\mathbf{4 . 7 3 1 , 1 2}$ & $\mathbf{1 3 . 6 4 7 , 5 4}$ & $\mathbf{4 0 . 4 3 3 , 3 0}$ \\
\hline
\end{tabular}

Quadro 9. Custo da etapa do plantio

Fonte: Dados da pesquisa.

O custo total com a etapa do plantio, sem a inclusão da depreciação, totalizou R440.433,30 em toda a área cultivada (65,5 hectares). Quando a cultura se encontra em fase inicial de crescimento, com aproximadamente 30 dias, o agricultor deve proceder à semeadura do cloreto de potássio. O tempo para realizar esta atividade, de acordo com o agricultor, é de 10 minutos por hectare. A quantidade de cloreto de potássio utilizada foi comum a todas as lavouras (2 sacas de $60 \mathrm{Kg}$ por hectare), com um preço unitário da saca de $\mathrm{R} \$ 53,50$. O custo relativo ao combustível utilizado na etapa de semeadura do cloreto de potássio foi obtido a partir do preço do combustível $(\mathrm{R} \$ 3,02)$ da quantidade por hectare $(1 \mathrm{~L} / \mathrm{ha}$.) e do total da área cultivada. No que diz respeito aos custos totais empregados na etapa de semeadura do cloreto de potássio, assim como os custos por lavoura, estes se encontram dispostos no Quadro 10.

\begin{tabular}{|l|c|c|c|c|c|}
\hline Descrição & $\begin{array}{c}\text { Lavoura } \\
\mathbf{1 ( R \mathbf { R } )}\end{array}$ & $\begin{array}{c}\text { Lavoura } \\
\mathbf{2 ( R \mathbf { }}\end{array}$ & $\begin{array}{c}\text { Lavoura } \\
\mathbf{3 ( R \mathbf { } )}\end{array}$ & Lavoura 4(R\$) & $\begin{array}{c}\text { Custo } \\
\text { total(R\$) }\end{array}$ \\
\hline $\begin{array}{l}\text { Cloreto de } \\
\text { potássio }\end{array}$ & $1.872,50$ & $2.247,00$ & 856,00 & $2.033,00$ & $7.008,50$ \\
\hline Combustível & 52,85 & 63,42 & 24,16 & 57,38 & 197,81 \\
\hline Custo total (R\$) & $\mathbf{1 . 9 2 5 , 3 5}$ & $\mathbf{2 . 3 1 0 , 4 2}$ & $\mathbf{8 8 0 , 1 6}$ & $\mathbf{2 . 0 9 0 , 3 8}$ & $\mathbf{7 . 2 0 6 , 3 1}$ \\
\hline
\end{tabular}

Quadro 10. Custo da etapa da semeadura do cloreto de potássio

Fonte: Dados da pesquisa.

Os custos da etapa da semeadura do cloreto de potássio, em toda a área cultivada (65,5 hectares), totalizam $\mathrm{R} \$ 7.206,31$. 
Custo da produção agrícola: uma análise do cultivo da soja em uma propriedade rural de Júlio de Castilhos/RS, safra 2016/2017

Yvelise Piccinin, Marivane Vestena Rossato

\subsubsection{Defensivos agrícolas}

A partir das orientações do engenheiro agrônomo e da experiência do produtor, além de necessidades específicas da lavoura, realizou-se a aplicação de defensivos agrícolas nas modalidades de: herbicida, fungicida e inseticida.

A lavoura 2 não necessitou de um quinto tratamento como as demais lavouras. $O$ custo com combustível nas aplicações dos defensivos agrícolas corresponde ao consumo de $1 \mathrm{~L} /$ ha. ao preço de $\mathrm{R} \$ 3,02$ e multiplicado pela quantidade de hectares e aplicações. No Quadro 11, encontram-se expressos os custos da etapa de aplicação de defensivos agrícolas no que diz respeito aos insumos utilizados e ao combustível consumido.

\begin{tabular}{|l|c|c|c|c|c|}
\hline Descrição & $\begin{array}{c}\text { Lavoura } \\
\mathbf{1 ( R \$ )}\end{array}$ & $\begin{array}{c}\text { Lavoura } \\
\mathbf{2 ( R \mathbf { }}\end{array}$ & $\begin{array}{c}\text { Lavoura } \\
\mathbf{3 ( R \mathbf { R } )}\end{array}$ & $\begin{array}{c}\text { Lavoura } \\
\mathbf{4}(\mathbf{R} \mathbf{\$})\end{array}$ & $\begin{array}{c}\text { Custo } \\
\text { total(R\$) }\end{array}$ \\
\hline Defensivos & $5.170,70$ & $5.092,35$ & $4.629,69$ & $7.492,78$ & $22.385,53$ \\
\hline Combustível & 264,25 & 253,68 & 120,80 & 286,90 & 925,63 \\
\hline Custo total(R\$) & $\mathbf{5 . 4 3 4 , 9 5}$ & $\mathbf{5 . 3 4 6 , 0 3}$ & $\mathbf{4 . 7 5 0 , 4 9}$ & $\mathbf{7 . 7 7 9 , 6 8}$ & $\mathbf{2 3 . 3 1 1 , 1 6}$ \\
\hline
\end{tabular}

Quadro 11. Custos da etapa da aplicação dos defensivos agrícolas

Fonte: Dados da pesquisa.

Percebe-se que os custos da etapa de aplicação dos defensivos agrícolas em toda a área cultivada $(65,5 \mathrm{ha})$ totalizam $R \$ 23.311,16$. Nas lavouras $1,2,3$ e 4 , os custos totalizaram $R \$ 5.434,95, \quad R \$ 5.346,03, \quad R \$ 4.750,49$ e $R \$ 7.779,68$, respectivamente. Ainda nesta etapa, para o produtor, não são gerados custos com mão de obra terceirizada, dado que o mesmo realiza sozinho. Cabe destacar que os custos referentes à depreciação e à manutenção encontram-se dispostos no final de todas as etapas do cultivo.

\subsubsection{Colheita e armazenamento}

Com a maturação da cultura da soja, realiza-se a colheita com o uso da colheitadeira e do caminhão (auxilia no transporte da produção colhida). Com relação ao custo relativo ao combustível utilizado na etapa de colheita da soja, este foi obtido a 
Custo da produção agrícola: uma análise do cultivo da soja em uma propriedade rural de Júlio de Castilhos/RS, safra 2016/2017

Yvelise Piccinin, Marivane Vestena Rossato

partir do preço do combustível ( $\mathrm{R} \$ 3,02)$, da quantidade utilizada para colher cada hectare (15 L/ha.) e do total da área colhida. No que diz respeito aos custos relativos à colheita realizada pela colheitadeira, estes se encontram dispostos no Quadro 12.

\begin{tabular}{|c|c|c|c|c|c|}
\hline Descrição & $\begin{array}{c}\text { Lavoura } \\
\mathbf{1 ( R \$ )}\end{array}$ & $\begin{array}{c}\text { Lavoura } \\
\mathbf{2 ( R \mathbf { R } )}\end{array}$ & $\begin{array}{c}\text { Lavoura } \\
\mathbf{3 ( R \mathbf { R } )}\end{array}$ & $\begin{array}{c}\text { Lavoura } \\
\mathbf{4 ( R \mathbf { } )}\end{array}$ & $\begin{array}{c}\text { Custo total } \\
\text { (R\$) }\end{array}$ \\
\hline Combustível & 792,75 & 951,30 & 362,40 & 860,70 & $2.967,15$ \\
\hline Mão-de-obra & 600,00 & 400,00 & 200,00 & 400,00 & $1.600,00$ \\
\hline Custo total(R\$) & $\mathbf{1 . 3 9 2 , 7 5}$ & $\mathbf{1 . 3 5 1 , 3 0}$ & $\mathbf{5 6 2 , 4 0}$ & $\mathbf{1 . 2 6 0 , 7 0}$ & $\mathbf{4 . 5 6 7 , 1 5}$ \\
\hline
\end{tabular}

Quadro 12. Custos da etapa da colheita

Fonte: Dados da pesquisa.

Na etapa da colheita, conforme disposto e individualizado por lavoura no Quadro 36 , obteve-se um custo de $R \$ 4.567,15$ para a realização da colheita de toda a área cultivada na propriedade (65,5 hectares) referentes ao combustível utilizado pela colheitadeira e mão de obra terceirizada ( $\mathrm{R} \$ 200,00$ ao dia).

Existem também os custos relativos ao diesel empregado no transporte da produção. Salienta-se que, conforme o produtor, a capacidade máxima do caminhão corresponde a $10.000 \mathrm{Kg}$. Ressalta-se que todas as distâncias se referem ao percurso total de ida e volta do caminhão, da lavoura à cooperativa, e o preço do óleo diesel foi de $\mathrm{R} \$ 3,02 /$ litro e o consumo é de $4 \mathrm{Km} / \mathrm{L}$ (Quadro 13). 
Custo da produção agrícola: uma análise do cultivo da soja em uma propriedade rural de Júlio de Castilhos/RS, safra 2016/2017

Yvelise Piccinin, Marivane Vestena Rossato

\begin{tabular}{|c|c|c|}
\hline Lavoura & De: & \\
\hline \multirow{3}{*}{ Lavoura 1} & Distância - lavoura e depósito (em km) & 28,2 \\
\hline & Quantidade de viagens & 8 \\
\hline & Custo combustível (R\$) & 170,33 \\
\hline \multirow{3}{*}{ Lavoura 2} & Distância - lavoura e depósito (em km) & 15,2 \\
\hline & Quantidade de viagens & 10 \\
\hline & Custo combustível $(\mathrm{R} \$)$ & 114,76 \\
\hline \multirow{3}{*}{ Lavoura 3} & Distância - lavoura e depósito (em km) & 6,4 \\
\hline & Quantidade de viagens & 4 \\
\hline & Custo combustível (R\$) & 19,33 \\
\hline \multirow{3}{*}{ Lavoura 4} & Distância - lavoura e depósito (em km) & 4,2 \\
\hline & Quantidade de viagens & 8 \\
\hline & Custo combustível (R\$) & 25,37 \\
\hline \multicolumn{2}{|c|}{ Custo total - combustível (R\$) } & 329,78 \\
\hline
\end{tabular}

Quadro 13. Custo combustível - transporte da colheita Fonte: Dados da pesquisa.

Os dados evidenciam que, para o transporte da colheita, foram gastos $R \$ 329,78$ com combustível, referente a todas as lavouras (30 descarregamentos). A lavoura 1 apresenta o maior gasto com combustível pelo motivo de sua distância ser maior que as demais.

\subsubsection{Depreciação e manutenção de máquinas e equipamentos}

No cálculo da depreciação de máquinas e equipamentos agrícolas, optou-se por não utilizar os critérios fiscais estabelecidos pela legislação brasileira, pois um cálculo realizado a uma taxa anual, geralmente, não condiz com o uso desses implementos; além do mais, os mesmos não são utilizados ininterruptamente durante o ano, em virtude de diversos fatores como entressafra, intempéries, ociosidades, dentre outros fatores.

Logo, a apropriação da depreciação atrelada às horas de utilização visou atribuir um custo à produção, de acordo com o efetivo uso dos utensílios agrícolas. Para a realização deste cálculo, adotou-se a metodologia proposta pela Companhia Nacional de Abastecimento (CONAB, 2010), delimitada em seu manual de Custos da Atividade 
Custo da produção agrícola: uma análise do cultivo da soja em uma propriedade rural de Júlio de Castilhos/RS, safra 2016/2017

Yvelise Piccinin, Marivane Vestena Rossato

Agrícola. O Quadro 14 demonstra as estimativas de vida útil, em horas e anos, bem como o valor residual. Salienta-se que apenas estão apresentados os índices determinados pela CONAB (2010) para os equipamentos e máquinas que o produtor utiliza e que, em função do ano de aquisição, são passíveis de depreciação, sendo que os demais não estão no quadro.

\begin{tabular}{|l|c|c|c|}
\hline Bem & Vida útil - anos & Vida útil - horas & Valor residual (\%) \\
\hline Colheitadeira & 10 & 5.000 & 25 \\
\hline Plantadeira & 15 & 1.200 & 20 \\
\hline Pulverizador & 8 & 2.000 & 5 \\
\hline Semeadeira direta & 15 & 1.200 & 20 \\
\hline Trator & 10 & 15.000 & 20 \\
\hline Veículo transbordo para grãos & 15 & 5.000 & 5 \\
\hline
\end{tabular}

Quadro 14. Vida útil de máquinas e equipamentos agrícolas (CONAB, 2010)

Fonte: Adaptado do Manual de Custos de produção agrícola: a metodologia da Conab, 2010.

Com os dados da CONAB, referentes à vida útil em horas dos equipamentos e máquinas agrícolas, procedeu-se ao cálculo da depreciação a partir do tempo de utilização informado pelo produtor. Conforme respostas obtidas, a etapa de dessecação demanda 20 minutos para ser realizada em cada hectare. O mesmo tempo é demandado para a aplicação de defensivos. Por outro lado, a semeadura do cloreto é bastante rápida, sendo necessários 10 minutos/ha. O plantio de cada hectare é realizado em 50 minutos e sua colheita em 48 minutos. Cumpre destacar, conforme já expresso anteriormente, que o trator 1 é utilizado apenas para o plantio, devido às suas características de potência. Do mesmo modo, o trator 2 é utilizado para a dessecação, aplicação de defensivos (5 aplicações nas lavouras 1, 3 e 4; e 4 aplicações na lavoura 2) e na semeadura do cloreto.

No Quadro 15, evidenciam-se os tempos totais de uso, em horas, de cada equipamento, em cada lavoura, de acordo com as características de utilização relatadas pelo agricultor. 
Custo da produção agrícola: uma análise do cultivo da soja em uma propriedade rural de Júlio de Castilhos/RS, safra 2016/2017

Yvelise Piccinin, Marivane Vestena Rossato

\begin{tabular}{|c|c|c|c|c|c|c|}
\hline \multirow{2}{*}{\multicolumn{2}{|c|}{$\begin{array}{c}\text { Máquina ou equipamento } \\
\text { utilizado }\end{array}$}} & \multicolumn{5}{|c|}{ Tempo de uso (em horas) } \\
\hline & & Lavoura 1 & Lavoura 2 & Lavoura 3 & Lavoura 4 & Total \\
\hline \multicolumn{2}{|l|}{ Colheitadeira } & 14 & 16,8 & 6,4 & 15,2 & 52,4 \\
\hline \multicolumn{2}{|l|}{ Plantadeira } & 14,58 & 17,5 & 6,67 & 15,83 & 54,58 \\
\hline \multirow{2}{*}{ Pulverizador } & Dessecar & 11,67 & 7 & 2,67 & 6,33 & 27,67 \\
\hline & Aplicar defensivos & 29,17 & 28 & 13,33 & 31,67 & 102,17 \\
\hline \multicolumn{2}{|c|}{ Semeadeira direta } & 2,92 & 3,5 & 1,33 & 3,17 & 10,92 \\
\hline \multicolumn{2}{|l|}{ Trator 1} & 14,58 & 17,5 & 6,67 & 15,83 & 54,58 \\
\hline \multirow{3}{*}{ Trator 2} & Dessecar & 5,83 & 7 & 2,67 & 6,33 & 21,83 \\
\hline & Semear cloreto & 2,92 & 3,5 & 1,33 & 3,17 & 10,92 \\
\hline & Aplicar defensivos & 29,17 & 28 & 13,33 & 31,67 & 102,17 \\
\hline \multicolumn{2}{|c|}{ Veículo transbordo para grãos } & - & - & - & - & - \\
\hline
\end{tabular}

Quadro 15. Utilização de máquinas e equipamentos (em horas)

Fonte: Dados da pesquisa.

Salienta-se que o veículo de transbordo de grãos corresponde ao caminhão e este foi adquirido em 1979, não cabendo mais considerar custo com depreciação. Com base nas horas expressas e na vida útil expressa em horas, realizou-se o cálculo da depreciação dos equipamentos e máquinas. Os valores estão no Quadro 16.

\begin{tabular}{|c|c|c|c|c|c|c|c|c|}
\hline \multirow{2}{*}{\multicolumn{2}{|c|}{$\begin{array}{c}\text { Máquina ou } \\
\text { equipamento } \\
\text { utilizado }\end{array}$}} & \multicolumn{2}{|c|}{ Descrição do bem } & \multicolumn{4}{|c|}{ Custo com depreciação (R\$) } & \multirow[b]{2}{*}{$\begin{array}{c}\text { Custo } \\
\text { total - } \\
\text { (R\$) }\end{array}$} \\
\hline & & $\begin{array}{l}\text { Valor do } \\
\text { bem(R\$) }\end{array}$ & $\begin{array}{l}\text { Valor } \\
\text { residual } \\
\text { (R\$) }\end{array}$ & $\begin{array}{c}\text { Lavoura } \\
1-(R \$)\end{array}$ & $\begin{array}{l}\text { Lavoura } \\
2-(R \$)\end{array}$ & $\begin{array}{l}\text { Lavoura } \\
3-(R \$)\end{array}$ & $\begin{array}{l}\text { Lavoura } \\
4-(R \$)\end{array}$ & \\
\hline \multicolumn{2}{|c|}{ Colheitadeira } & $129.000,00$ & $32.250,00$ & 270,90 & 325,08 & 123,84 & 294,12 & $1.013,94$ \\
\hline \multicolumn{2}{|c|}{ Plantadeira } & $23.000,00$ & $4.600,00$ & 223,61 & 268,33 & 102,22 & 242,78 & 836,94 \\
\hline \multirow[b]{2}{*}{ Pulverizador } & Dessecar & $28.000,00$ & $1.400,00$ & 155,17 & 93,10 & 35,47 & 84,23 & 367,97 \\
\hline & \begin{tabular}{|l|} 
Aplicar \\
defensivos
\end{tabular} & $28.000,00$ & $1.400,00$ & 387,92 & 372,40 & 177,33 & 421,17 & $1.358,82$ \\
\hline \multicolumn{2}{|c|}{ Semeadeira direta } & $2.000,00$ & 400,00 & 3,89 & 4,67 & 1,78 & 4,22 & 14,56 \\
\hline \multicolumn{2}{|c|}{ Trator 1} & $56.000,00$ & $11.200,00$ & 43,56 & 52,27 & 19,91 & 47,29 & 163,02 \\
\hline \multirow{3}{*}{ Trator 2} & \begin{tabular}{|l|} 
Dessecar \\
\end{tabular} & $93.000,00$ & $18.600,00$ & 28,93 & 34,72 & 13,23 & 31,41 & 108,29 \\
\hline & \begin{tabular}{|l|l|}
$\begin{array}{l}\text { Semear } \\
\text { cloreto }\end{array}$ \\
\end{tabular} & $93.000,00$ & $18.600,00$ & 14,47 & 17,36 & 6,61 & 15,71 & 54,15 \\
\hline & \begin{tabular}{|l|} 
Aplicar \\
defensivos
\end{tabular} & $93.000,00$ & $18.600,00$ & 144,67 & 138,88 & 66,13 & 157,07 & 506,75 \\
\hline \multicolumn{4}{|c|}{ Custo total com depreciação (R\$) } & & & & & $4.424,43$ \\
\hline
\end{tabular}

Quadro 16. Depreciação de máquinas e equipamentos por atividade e seu total Fonte: Dados da pesquisa.

Para a depreciação das máquinas e equipamentos, obteve-se um custo total com depreciação de $R \$ 4.424,43$. A lavoura 1 apresentou uma depreciação referente a todos 
Custo da produção agrícola: uma análise do cultivo da soja em uma propriedade rural de Júlio de Castilhos/RS, safra 2016/2017

Yvelise Piccinin, Marivane Vestena Rossato

os bens utilizados igual a $R \$ 1.273,11$; já a lavoura 2 , $R \$ 1.306,81$. Além disso, nas lavouras 3 e 4, o custo de depreciação correspondeu a $R \$ 546,52$ e $R \$ 1.298,00$, respectivamente.

Além da depreciação, que corresponde a um custo não desembolsável, o produtor incorre em outros gastos. Estes se referem à manutenção periódica dos seus implementos agrícolas, realizada a cada início de safra ou quando se faz necessária. As peças e lubrificantes geraram um custo de $R \$ 3.610,82$ ao produtor, conforme notas fiscais. Além destes, o produtor necessitou realizar a revisão dos tratores e da colheitadeira. Os valores dos mesmos, bem como a apropriação deste custo às lavouras encontram-se no Quadro 17. Frisa-se que o rateio foi realizado de acordo com a área cultivada.

\begin{tabular}{|l|c|c|c|c|c|}
\hline \multicolumn{1}{|c|}{ Descrição } & $\begin{array}{c}\text { Custo - } \\
(\mathbf{R} \$)\end{array}$ & $\begin{array}{c}\text { Lavoura } \\
\mathbf{1 ( R \$ )}\end{array}$ & Lavoura 2(R\$) & Lavoura 3(R\$) & Lavoura 4(R\$) \\
\hline Manutenção trator 1 & $1.710,00$ & 456,87 & 548,24 & 208,85 & 496,03 \\
\hline Manutenção trator 2 & $1.493,00$ & 398,89 & 478,67 & 182,35 & 433,08 \\
\hline Manut. colheitadeira & $6.950,00$ & $1.856,87$ & $2.228,24$ & 848,85 & $2.016,03$ \\
\hline $\begin{array}{l}\text { Peças } \\
\text { lubrificantes }\end{array}$ & $3.610,82$ & 964,72 & $1.157,67$ & 441,02 & $1.047,41$ \\
\hline Custo total (R\$) & $13.763,82$ & $3.677,36$ & $4.412,83$ & $1.681,08$ & $3.992,56$ \\
\hline
\end{tabular}

Quadro 17. Manutenção de máquinas e equipamentos

Fonte: Dados da pesquisa.

$\mathrm{Na}$ manutenção das máquinas e equipamentos, obteve-se um custo total com manutenção de $R \$ 13.763,82$. Na lavoura 1, foi apropriado um custo de manutenção igual a $R \$ 3.677,36$. Já a lavoura 2 recebeu um custo de $R \$ 4.412,83$ e, nas lavouras 3 e 4 , o custo de manutenção correspondeu a $R \$ 1.681,08$ e $R \$ 3.992,56$, respectivamente.

\subsubsection{Delimitação dos custos totais de produção da soja}

No Quadro 18, apresentam-se os dados referentes aos custos apurados em cada etapa, por atividade, bem como todos os custos da produção da soja agrupados para cada lavoura e o custo total de produção. 
Custo da produção agrícola: uma análise do cultivo da soja em uma propriedade rural de Júlio de Castilhos/RS, safra 2016/2017

Yvelise Piccinin, Marivane Vestena Rossato

\begin{tabular}{|c|c|c|c|c|c|c|}
\hline \multirow{2}{*}{\multicolumn{2}{|c|}{ Etapa }} & \multicolumn{4}{|c|}{ Custo por lavoura (R\$) } & \multirow{2}{*}{$\begin{array}{c}\text { Custo total } \\
\text { (R\$) }\end{array}$} \\
\hline & & Lavoura 1 & Lavoura 2 & Lavoura 3 & Lavoura 4 & \\
\hline \multicolumn{2}{|l|}{ 1) Calagem } & $1.837,50$ & $2.205,00$ & 840,00 & $1.995,00$ & $6.877,50$ \\
\hline \multirow{3}{*}{ 2) Dessecar } & Defensivos & $2.177,00$ & $2.045,40$ & 444,80 & 777,10 & $5.444,30$ \\
\hline & Depreciação & 155,17 & 93,10 & 35,47 & 84,23 & 367,97 \\
\hline & Combustível & 105,70 & 63,42 & 24,16 & 57,38 & 250,66 \\
\hline \multirow{5}{*}{ 3) Plantio } & Sementes & 556,50 & 649,25 & 212,00 & $4.970,88$ & $6.388,63$ \\
\hline & Adubo & $8.925,00$ & $10.710,00$ & $4.250,00$ & $8.075,00$ & $31.960,00$ \\
\hline & Depreciação & 267,17 & 311,89 & 145,78 & 286,33 & $1.011,17$ \\
\hline & Combustível & 369,95 & 443,94 & 169,12 & 401,66 & $1.384,67$ \\
\hline & Mão de obra & 200,00 & 200,00 & 100,00 & 200,00 & 700,00 \\
\hline \multirow{3}{*}{$\begin{array}{l}\text { 4) Semear } \\
\text { cloreto de } \\
\text { potássio }\end{array}$} & Cloreto & $1.872,50$ & $2.247,00$ & 856,00 & 2.033 & $7.008,50$ \\
\hline & Depreciação & 18,36 & 22,03 & 8,39 & 19,93 & 68,70 \\
\hline & Combustível & 52,85 & 63,42 & 24,16 & 57,38 & 197,81 \\
\hline \multirow{3}{*}{$\begin{array}{l}\text { 5) Aplicação } \\
\text { de defensivos }\end{array}$} & Defensivos & $5.170,70$ & $5.092,35$ & $4.629,69$ & $7.492,78$ & $22.385,53$ \\
\hline & Depreciação & 387,92 & 372,40 & 177,33 & 421,17 & $1.358,82$ \\
\hline & Combustível & 264,25 & 253,68 & 120,80 & 286,90 & 925,63 \\
\hline \multirow{3}{*}{ 6) Colheita } & Depreciação & 270,90 & 325,08 & 123,84 & 294,12 & $1.013,94$ \\
\hline & Combustível & 792,75 & 951,30 & 362,40 & 860,70 & $2.967,15$ \\
\hline & Mão de obra & 600,00 & 400,00 & 200,00 & 400,00 & $1.600,00$ \\
\hline 7) Caminhão & Combustível & 170,33 & 114,76 & 19,33 & 25,37 & 329,78 \\
\hline \multicolumn{2}{|l|}{ 8) Manutenção } & $3.677,36$ & $4.412,83$ & $1.681,08$ & $3.992,56$ & $13.763,82$ \\
\hline \multicolumn{2}{|c|}{ Custo total (R\$) } & $27.871,89$ & $30.976,85$ & $14.424,34$ & $32.731,49$ & $106.004,57$ \\
\hline
\end{tabular}

Quadro 18. Custo por etapa, por lavoura e total, do cultivo da soja

Fonte: Dados da pesquisa.

Os resultados evidenciados revelaram que o custo total envolvido na produção da soja, na safra 2016/2017, importou em $R \$ 106.004,57$. Por lavoura (1, 2, 3 e 4), os gastos corresponderam a: $R \$ 27.871,89$; $R \$ 30.976,85 ; R \$ 14.424,34$; e $R \$ 32.731,49$, respectivamente. No Quadro 19, expressa-se o custo de produção da soja em cada lavoura cultivada, bem como o custo da saca produzida em cada lavoura e o custo médio de produção em toda a área plantada. 
Custo da produção agrícola: uma análise do cultivo da soja em uma propriedade rural de Júlio de Castilhos/RS, safra 2016/2017

Yvelise Piccinin, Marivane Vestena Rossato

\begin{tabular}{|c|c|c|c|c|}
\hline Lavoura & $\begin{array}{c}\text { Custo de } \\
\text { produção (R\$) }\end{array}$ & $\begin{array}{c}\text { Produção } \\
\text { (sacas de 60 Kg) }\end{array}$ & $\begin{array}{c}\text { Produção } \\
\text { (sacas de 60 Kg/ha) }\end{array}$ & $\begin{array}{c}\text { Custo unitário } \\
\text { (saca 60 Kg) }\end{array}$ \\
\hline 1 & $27.871,89$ & 1.225 & 70 & 22,75 \\
\hline 2 & $30.976,85$ & 1.659 & 79 & 18,67 \\
\hline 3 & $14.424,34$ & 568 & 71 & 25,39 \\
\hline 4 & $32.731,49$ & 1.235 & 65 & 26,50 \\
\hline Custo total(R\$) & $\mathbf{1 0 6 . 0 0 4 , 5 7}$ & $\mathbf{4 . 6 8 7}$ & $\mathbf{7 1 , 5 6}$ & $\mathbf{2 2 , 6 2}$ \\
\hline
\end{tabular}

Quadro 19. Custo de produção da soja - por lavoura e por saca

Fonte: Dados da pesquisa.

Verifica-se que o custo de produção da lavoura 4 correspondeu ao maior custo de produção, assim como ao maior custo por saca produzida ( $R \$ 26,50)$. Muito provavelmente, tal fato esteja atrelado ao fato de o custo da semente ser superior e pelo menor rendimento que a mesma proporcionou em comparação com as demais lavouras cultivadas.

Por fim, a lavoura 2 apresentou o menor custo de produção para cada saca colhida, $R \$ 18,67$. Isto provavelmente se deva ao fato de que a mesma lavoura não demandou um quinto tratamento com defensivos agrícolas como as demais, bem como pela produção mais elevada de 79 sacas/hectare. Observa-se também que, em média, o custo da produção de uma saca de soja de 60 quilos é de $R \$ 22,62$.

Com base nos custos anteriores e nas receitas informadas pelo produtor, procedeu-se à apuração do resultado líquido obtido com a cultura da soja na safra de 2016/2017. Assim, ao se indagar ao produtor sobre as vendas realizadas, este afirmou que realizou duas vendas de soja, ambas de 1.500 sacas/cada. Na primeira venda, o valor obtido pela saca vendida obtida foi de $R \$ 63,00$ e, na segunda, de $R \$ 58,00$.

Cabe destacar que o mesmo não vendeu toda sua produção, porque a está realizando conforme a necessidade de pagamento das dívidas contraídas. Desse modo, para as sacas de soja restantes (1.687), estabeleceu-se como referência a cotação do dia 23 de maio de 2017, correspondente à $R \$ 61,00$, tendo em vista ser o dia em que se procedeu à apuração do resultado, para fins de elaboração deste estudo.

$\mathrm{Na}$ primeira venda, o produtor obteve a receita bruta de $\mathrm{R} \$ 94.500,00$ (1.500 sacas de soja à $R \$ 63,00$ ); na segunda venda, $R \$ 87.000,00$ (1.500 sacas a $R \$ 58,00$ ). 
Custo da produção agrícola: uma análise do cultivo da soja em uma propriedade rural de Júlio de Castilhos/RS, safra 2016/2017

Yvelise Piccinin, Marivane Vestena Rossato

Por fim, se o produtor houvesse realizado a venda da produção restante de acordo com a cotação do dia 23/05/2017, este obteria uma receita bruta de $R \$ 102.907,00$, totalizando $R \$ 284.407,00$ referentes a toda a produção da safra 2016/2017.

Desse modo, o custo de produção representa aproximadamente $37,27 \%$ da receita bruta (custo de produção $\mathrm{R} \$ 106.004,57$ em relação à receita bruta de $\mathrm{R} \$ 284.407,00)$.

\section{CONCLUSÃO}

A atividade rural requer diversos cuidados e a aplicação de múltiplos insumos volumosos para a produção da cultura. Desse modo, a problemática desta pesquisa consistiu na falta de dados e informações de caráter operacional que pudessem delimitar os custos atrelados à atividade do cultivo da soja, bem como a avaliação do custo médio da saca de soja produzida.

Para a resolução da problemática e do atendimento ao objetivo, inicialmente se caracterizou o cultivo da soja e a propriedade no que se refere à área cultivada e às máquinas e equipamentos utilizados. Na especificação da produção da soja, adotou-se a metodologia proposta por Hirakuri et al. (2012), juntamente com as características próprias do cultivo nesta propriedade, onde as etapas correspondem a: (1) calagem, gessagem e dessecação; (2) semeadura e adubação - sementes, tratamento e inoculação das sementes, plantio, adubação da base e semeadura de cloreto de potássio; (3) controle fitossanitário - plantas daninhas, insetos-praga e doenças; (4) colheita e transporte externo; e (5) pós-colheita - secagem, armazenagem e transporte. Também delimitaram-se a área cultivada e as máquinas e equipamentos utilizados.

Realizada tal etapa, procedeu-se à identificação e apuração dos gastos associados ao cultivo e comercialização da soja na propriedade rural. Os resultados dessas apurações revelaram que o custo total envolvido na produção da soja, na safra 2016/2017, importou em $R \$ 106.004,57$. Por lavoura $(1,2,3$ e 4$)$, os gastos corresponderam a: $R \$ 27.871,89 ; \quad R \$ 30.976,85 ; \quad R \$ 14.424,34 ;$ e $R \$ 32.731,49$, 
Custo da produção agrícola: uma análise do cultivo da soja em uma propriedade rural de Júlio de Castilhos/RS, safra 2016/2017

Yvelise Piccinin, Marivane Vestena Rossato

respectivamente. Ainda revelaram um custo médio de $\mathrm{R} \$ 22,62$ por saca de soja produzida (4.687 sacas colhidas).

Por fim, o custo de produção representa, aproximadamente, $37,27 \%$ da receita bruta (custo de produção $R \$ 106.004,57$ em relação à receita bruta de $R \$ 284.407,00$ ). Cumpre destacar que os resultados do cultivo da soja variam de safra para safra, pois dependem diretamente dos fatores climáticos ocorridos no período.

Como limitações, destaca-se o fato de esta pesquisa ser um estudo de caso, o que gera resultados aplicáveis apenas a esta propriedade. Além disso, estes resultados podem não se aplicar em anos subsequentes, visto que os que aqui foram apurados refletem os fatores referentes à safra de 2016/2017 e às características peculiares desse período.

Para estudos futuros, sugere-se a replicação do estudo em outra propriedade para se avaliar os custos envolvidos no cultivo da soja bem como o custo da saca de soja produzida, com fins de se avaliar as diferenças existentes em outra propriedade.

\section{REFERÊNCIAS}

Batalha, M. O., \& Queiroz, T. R. (2003). Tomada de decisões em propriedades agrícolas familiares: $O$ uso dos sistemas de custeio e indicadores de desempenho. JCEA; Universidade Federal de Mato Grosso do Sul.

Belei, R. A. (2008). O uso de entrevista, observação e vídeo gravação em pesquisa qualitativa. Cadernos de Educação. Pelotas, 30, 187-199.

Brasil. Lei n. 4.504, de 30 de novembro de 1964. Dispõe sobre o Estatuto da Terra e dá outras providências. Diário Oficial da União, Brasília, DF, 31 nov. (1964). Recuperado de: <http://presrepublica.jusbrasil.com.br/legislacao/104451/estatutoda-terra-lei-4504-64>. Acesso em: 11 out. 2016.

. Ministério da Agricultura, Pecuária e Abastecimento. Companhia Nacional de Abastecimento - Conab. Custos de produção agrícola: a metodologia da Conab. Brasília, DF, 2010. Recuperado de: $<$ http://www.conab.gov.br/conabweb/download/safra/custos.pdf $>$. Acesso em: 05 jan. 2017. 
Custo da produção agrícola: uma análise do cultivo da soja em uma propriedade rural de Júlio de Castilhos/RS, safra 2016/2017

Yvelise Piccinin, Marivane Vestena Rossato

Crepaldi, S. A. (2016). Contabilidade rural: uma abordagem decisorial. (8a. ed.). São Paulo, Atlas.

Empresa Brasileira de Pesquisa Agropecuária (EMBRAPA) - História da soja. Londrina, 2016. Recuperado de: <https://www.embrapa.br/web/portal/soja/cultivos/ soja1/historia>. Acesso em: 11 nov. 2016.

Freitas, L. A. R., Kesseler, N. S., Piccinin, Y., Rossato, M. V., \& Dorr, A. C. (2014). Gestão rural e práticas sustentáveis na atividade de agricultura familiar. In: DÖRR, A. C. et al. Práticas e saberes em meio ambiente. (1a. ed.). Curitiba, Appris.

Gil, A. C. (2012). Métodos e técnicas de pesquisa social. (6a. ed.). São Paulo, Atlas.

Hirakuri, M. H., Debiasi, H., Procópio, S. O., Franchini, J. C., \& Castro, C. Sistemas de Produção: conceitos e definições no contexto agrícola. Londrina: Embrapa Soja, 2012. (Documentos, n. 335). Recuperado de: <http://www.infoteca.cnptia.embrapa.br/bitstream/doc/938807/1/Doc335OL.pdf>. Acesso em: 17/mar./2017.

Leone, G. S. G., \& Leone, R. J. G. (2010). Curso de contabilidade de custos. (4a. ed.). São Paulo, Atlas.

Marion, J. C. (2014). Contabilidade rural: contabilidade agrícola, contabilidade da pecuária. (14a. ed.). São Paulo, Atlas.

Marion, J. C., \& Ribeiro, O. M. (2011). Introdução à contabilidade gerencial. (1a. ed.). São Paulo: Saraiva.

Martins, E. (2010). Contabilidade de custos. (10a. ed.). São Paulo: Atlas.

Michel, M. H. (2015). Metodologia e pesquisa científica em ciências sociais: um guia prático para acompanhamento da disciplina e elaboração de trabalhos monográficos. (3a. ed.). São Paulo, Atlas.

Padoveze, C. L. (2013). Contabilidade de custos: teoria, pratica, Integração com Sistemas de Informações (ERP). São Paulo, Cengage Learning.

Ribeiro, O. M. (2015). Contabilidade de custos. (4a. ed.). São Paulo, Saraiva.

Rodrigues, A. J. (2010). Metodologia científica: série bibliográfica unit. (3a. ed.). Aracaju, UNIT. 
Custo da produção agrícola: uma análise do cultivo da soja em uma propriedade rural de Júlio de

Schwert, L. D., \& Cruz, V. R. L. (2013). Apuração de custos em uma propriedade rural do município de Dilermando de Aguiar/RS. (Trabalho de Conclusão de Curso). Universidade Federal de Santa Maria - UFSM, Santa Maria, RS, Brasil.

Seramim, R. J., \& Rojo, C. A. (2016). Gestão dos custos de produção da atividade leiteira na agricultura familiar. Revista Gestão \& Tecnologia, 16(3), 244-260.

Venturini, H. P. (2016). Estudo sobre a viabilidade econômica de uma lavoura de soja no município de Restinga Seca. (Trabalho de Conclusão de Curso). Universidade Federal de Santa Maria - UFSM, Santa Maria, RS, Brasil.

Viceconti, P., \& Neves, S. (2013). Contabilidade Básica. (16a. ed.). São Paulo, Saraiva.

Yin, R. K. (2010). Estudo de caso: planejamento e métodos. (4a. ed.). Porto Alegre, Bookman.

Data de Submissão: 18/09/2018

Data de Aceite: 12/12/2018 